\title{
Pengembangan Kriteria Seleksi untuk Perakitan Terung (Solanum melongena L.) Berdaya Hasil Tinggi
}

\section{Development of Selection Criteria for Breeding High Yielding Eggplant (이anum melongena L.)}

\author{
Faradila Danasworo Putri' ${ }^{1}$ Sobir $^{2 *}$, Muhamad Syukur², dan Awang Maharijaya ${ }^{2}$ \\ 'Program Studi Pemuliaan dan Bioteknologi Tanaman, Sekolah Pascasarjana, Institut Pertanian Bogor \\ ${ }^{2}$ Departemen Agronomi dan Hortikultura, Fakultas Pertanian, Institut Pertanian Bogor \\ (Bogor Agricultural University), Jl. Meranti, Kampus IPB Darmaga, Bogor 16680, Indonesia
}

Diterima 16 Maret 2016/Disetujui 21 September 2016

\begin{abstract}
Eggplants (Solanum melongena L.) are consumed worldwide in a variety of colors, shapes and sizes, thus vegetable plant breeders place great interest in developing high yielding genotypes in response to the population growth and the need to increase vegetable production. This research was aimed to determine the proper character as selection character for breeding high yielding eggplants by using estimated heritability value, coefficient of genetic diversity, characters correlation and path analysis. The experiment was conducted during 2014 to August 2015 at Cikabayan Experimental Field, Tajur Experimental Field and Pasir Sarongge Experimental Field, IPB, West Java. A total of 12 characters was observed in the 25 genotypes. Eleven characters has a high estimated heritability value and high coefficient of genetic diversity value. Those characters were time of flowering, time of harvest, fruit length, fruit weight, fruit diameter, plant height, stem length, fruit apical scar length, calyx length, the number of fruits per plant and fruit weight per plant. Results of correlation and path analysis showed that fruit length, fruit weight, fruit diameter, stem diameter, calyx length and number of fruits per plant have a direct positive effect on fruit weight per plant. Fruit weight, fruit diameter and number of fruits per plant are suitable characters in determining the selection criteria for developing high productivity eggplant.
\end{abstract}

Keywords: path analysis, correlation, heritability, genetic diversity coefficient

\section{ABSTRAK}

Terung (Solanum melongena L.) dikonsumsi diseluruh dunia dalam berbagai warna, bentuk dan ukuran sehingga pemulia tanaman sayur tertarik untuk mengembangkan genotipe berdaya hasil tinggi seiring dengan perkembangan populasi dan kebutuhan untuk meningkatkan produksi sayuran. Penelitian ini bertujuan untuk menentukan karakter yang tepat sebagai karakter seleksi untuk perakitan terung berdaya hasil tinggi melalui pendugaan nilai heritabilitas, koefisien keragaman genetik, korelasi antar karakter dan analisis lintas. Penelitian dilaksanakan pada bulan Mei 2014 hingga Agustus 2015 di Kebun Percobaan (KP) Cikabayan, KP Tajur dan KP Pasir Sarongge. Sebanyak 12 karakter diamati pada 25 genotipe yang digunakan dalam penelitian ini. Sebelas karakter memiliki heritabilitas tinggi dan koefisien keragaman genetik tinggi, yaitu umur berbunga, umur berbuah, panjang buah, bobot buah, diameter buah, tinggi tanaman, panjang tangkai, lebar bekas putik, ukuran calyx, jumlah buah per tanaman dan bobot buah per tanaman. Hasil analisis korelasi dan analisis lintas menunjukkan bahwa panjang buah, bobot buah, diameter buah, diameter batang, ukuran calyx dan jumlah buah per tanaman memiliki pengaruh langsung positif terhadap karakter bobot buah per tanaman. Bobot buah, diameter buah dan jumlah buah per tanaman merupakan karakter yang tepat dalam penentuan kriteria seleksi untuk merakit terung berproduksi tinggi.

Kata kunci: analisis sidik lintas, korelasi, heritabilitas, koefisien keragaman genetik

\section{PENDAHULUAN}

Terung (Solanum melongena L.) merupakan sayuran yang bernilai ekonomi tinggi dan dapat memberikan manfaat bagi kesehatan manusia. Buah ini dikonsumsi

\footnotetext{
* Penulis untuk korespondensi. e-mail: sobir@ipb.ac.id
}

diseluruh dunia dalam berbagai warna, bentuk dan ukuran (Akanitapichat et al., 2010). Terung telah dibudidayakan secara luas di daerah tropis dan subtropis, terutama di Asia (Sathappan et al., 2012) dimana beberapa negara produsen terbesar antara lain adalah Cina, India, Mesir, Turki dan Indonesia. Tanaman ini memiliki hasil produksi global sebanyak lebih dari 32 juta ton dengan (Begum et al., 2013). 
Dengan berkembangnya populasi dan kebutuhan untuk meningkatkan produksi sayuran di negara Asia, pemulia tanaman sayur tertarik untuk mengembangkan genotipe terung (Kumar et al., 2013).

Pemulia tanaman hortikultura selalu dihadapkan dengan kebutuhan untuk memperbaiki sifat tanaman, salah satu diantaranya adalah daya hasil (Luby dan Shaw, 2009). Daya hasil merupakan karakter kompleks yang dikendalikan oleh banyak gen dan dipengaruhi oleh karakter komponen hasil, karakter agronomi lainnya serta lingkungan. Sebelum memulai suatu program pemuliaan, tantangan yang dihadapi para pemulia adalah menentukan karakter penting yang dapat membantu mencapai tujuan pemuliaan. Karakter penting tersebut kemudian dijadikan kriteria seleksi dalam program pemuliaan. Kunci keberhasilan suatu seleksi ditentukan oleh kriteria seleksi yang sesuai. Analisis hubungan antar karakter diperlukan agar dapat menentukan kriteria seleksi yang efektif.

Hubungan antar karakter dapat diketahui dari analisi korelasi. Selain analisis korelasi, analisis lintas (path analysis) digunakan karena dapat membedakan pengaruh langsung suatu karakter serta pengaruh tidak langsung melalui karakter lain (Thangamani dan Jansirani, 2012). Analisis lintas kerap digunakan untuk menentukan kriteria seleksi tanaman Solanaceae, seperti cabai (Syukur et al., 2010), tomat (Hidayatullah et al., 2008), kentang (Khayatnezhad et al., 2011), dan terung (Bansal dan Mehta, 2008). Parameter lain yang digunakan untuk menentukan apakah suatu karakter dapat dijadikan kriteria seleksi adalah nilai heritabilitas, ragam genetik, ragam fenotipe dan koefisien keragaman genetik (KKG) (Yunianti et al., 2010).

Penelitian ini bertujuan untuk menentukan karakter yang tepat sebagai karakter seleksi untuk perakitan terung berdaya hasil tinggi melalui pendugaan nilai heritabilitas, koefisien keragaman genetik, korelasi antar karakter, dan analisis lintas.

\section{BAHAN DAN METODE}

Penelitian dilaksanakan pada bulan Mei 2014 sampai dengan Agustus 2015 di tiga kebun percobaan yang berbeda milik University Farm dan Pusat Studi Hortikultura Tropis (PKHT), Institut Pertanian Bogor. Tiga kebun percobaan tersebut adalah Kebun Percobaan (KP) Cikabayan (6 ${ }^{\circ} 55^{\prime} 13.23$ ' S, 106 71'53.6" E) dengan ketinggian $160 \mathrm{~m}$ di atas permukaan laut, KP Tajur (6 $63^{\circ} 62.4^{\prime \prime} \mathrm{S}, 106^{\circ} 82,34^{\prime \prime}$ E) dengan ketinggian $340 \mathrm{~m}$ di atas permukaan laut, dan KP Pasir Sarongge (66'64.07' S, 10704'96.09'” E) dengan ketinggian $1.105 \mathrm{~m}$ di atas permukaan laut.

Bahan genetik yang digunakan untuk percobaan ini adalah 25 genotipe terung yang terdiri atas 2 genotipe koleksi PKHT yaitu TUP (G1) dan THP (G2); 5 varietas komersial yaitu Bruno (G3), Pulus (G4), Hijo (G5), Ronggo (G6) dan Sriti (G7); dan 18 genotipe lokal hasil eksplorasi dari Jawa Timur yaitu 2013-057-1 (G8), 2014-040 (G9), 2014-033 (G10), 2014-013 (G11), 2014-052 (G12), 2014032 (G13), 2014-024 (G14), 2014-029 (G15), 2014-067
(G16), 2014-080 (G17), 2014-050 (G18), 2014-044 (G19), 2014-034 (G20), 2014-054 (G21), 2014-008 (G22), 2014047 (G23), 2014-077 (G24) dan 2014-071 (G25).

Bibit yang memiliki daun 4-6 helai atau berumur lima minggu dipindahtanamkan secara manual ke dalam petak berukuran $5 \mathrm{~m}$ x $1 \mathrm{~m}$. Jarak tanam antar bibit adalah sebesar $50 \mathrm{~cm}$ x $50 \mathrm{~cm}$ dan sebanyak 10 dari 20 tanaman di masingmasing petak dipilih untuk pengamatan karakter komponen hasil. Pemanenan dilakukan secara manual ketika buah sudah tidak terlalu lunak sehingga benih belum terbentuk di dalam daging buah. Periode pemanenan berlangsung dari umur panen hingga 7 minggu setelah umur panen.

Karakter yang diamati adalah (1) panjang buah, (2) diameter buah, (3) bobot buah, (4) tinggi tanaman pada umur 2 minggu setelah panen, (5) diameter batang setinggi $10 \mathrm{~cm}$ diatas permukaan tanah pada umur 2 minggu setelah panen, (6) panjang tangkai buah, (7) ukuran calyx (UC) diperoleh dari mengukur panjang sepal yang terdapat pada bagian atas buah terung, (8) lebar bekas putik (LBP) diperoleh dari mengukur bekas putik yang berada di dasar buah, (9) umur berbunga (UBN) dihitung dari saat pindah tanam hingga $50 \%$ populasi berbunga, (10) umur berbuah (UB) dihitung dari saat pindah tanam hingga $50 \%$ populasi memiliki buah yang siap panen, (11) jumlah buah per tanaman dan (12) bobot buah per tanaman.

Analisis data yang dilakukan antara lain adalah perhitungan nilai heritabilitas $\left(\mathrm{h}^{2}\right)$, koefisien keragaman genetik (KKG), analisis korelasi Pearson dan analisis lintas (path analysis). Analisis dilakukan dengan menggunakan perangkat lunak Minitab 14 dan SAS 9.

Perhitungan nilai ragam genetik $\left(\sigma^{2} \mathrm{~g}\right)$, heritabilitas $\left(\mathrm{h}^{2}\right)$, koefisien keragaman genetik (KKG) dilakukan dilakukan berdasarkan pemisahan nilai kuadrat tengah harapan dari rancangan kelompok lengkap teracak dengan menggunakan persamaan: (i) $\sigma_{g}^{2}=\frac{\mathrm{KT}_{\mathrm{g}}-\mathrm{KT}_{\mathrm{e}}}{\mathrm{r}}$

(ii) $\mathrm{h}_{\mathrm{bs}}^{2}=\frac{\sigma^{2} \mathrm{~g}}{\sigma^{2} \mathrm{p}} \times 100 \%=\frac{\sigma^{2} \mathrm{~g}}{\left(\sigma^{2} \mathrm{~g}^{+} \sigma_{\mathrm{g} / \mathrm{e}}^{2} / 1+\sigma^{2} / \mathrm{rl}\right)} \times 100 \%$

(iii) $\mathrm{KKG}=\frac{\sqrt{\sigma^{2}}}{\overline{\mathrm{x}}} \times 100 \%$

(Keterangan : $\mathrm{KT}_{\mathrm{e}}=$ kuadrat tengah galat; $\mathrm{KT}_{\mathrm{g}}=$ kuadrat tengah genotipe; $r=$ jumlah ulangan; $1=$ jumlah lokasi; $\sigma^{2} p$ = ragam fenotip; $\sigma^{2}$ gxe $=$ ragam interaksi genotipe dengan lingkungan; $\bar{x}=$ nilai tengah seluruh genotipe)

Nilai KKG dapat dikategorikan luas atau sempit dengan menggunakan standar deviasi ragam genetik dengan persamaan :

$$
\text { (iv) } \sigma_{\sigma^{2}}=\sqrt{\frac{2}{\mathrm{r}^{2}}\left[\frac{\mathrm{KT}_{\mathrm{g}}^{2}}{\mathrm{db}_{\mathrm{g}}+2}+\frac{\mathrm{KT}_{\mathrm{e}}^{2}}{\mathrm{db}_{\mathrm{e}}+2}\right]}
$$

(Keterangan: $\mathrm{KT}_{\mathrm{e}}=$ kuadrat tengah galat; $\mathrm{KT}_{\mathrm{g}}=$ kuadrat tengah genotipe; $\mathrm{r}=$ ulangan; $\mathrm{db}_{\mathrm{g}}=$ derajat bebas genotipe; $\mathrm{db}_{\mathrm{e}}=$ derajat bebas galat). Pinaria et al. (1995) menyatakan keragaman genetik suatu karakter luas apabila $2 \sigma_{\sigma \mathrm{g}}^{2}<\sigma_{\mathrm{g}}^{2}$ dan keragaman genetik sempit apabila $2 \sigma_{\sigma \mathrm{g}}^{2}>\sigma_{\mathrm{g}}^{2}$.

Korelasi fenotipik dengan menggunakan korelasi Pearson dilakukan untuk melihat keeratan hubungan antar 
karakter yang diamati pada tanaman dan buah terung. Nilai koefisien korelasi Pearson diuji pada taraf $\alpha=5 \%$ dan $\alpha=$ $1 \%$. Analisis lintas dilakukan berdasarkan metode matriks Singh dan Chaudhary (1979).

\section{HASIL DAN PEMBAHASAN}

Nilai pendugaan ragam genetik, KKG, standar deviasi ragam genetik dan heritabilitas masing-masing karakter disajikan pada Tabel 1. Semua karakter yang diamati pada tanaman dan buah terung memiliki keragaman genetik yang luas dan heritabilitas yang tinggi, kecuali untuk karakter diameter batang. KKG karakter yang diamati berkisar antara 4.06-56.81\%. Luas atau sempitnya koefisien keragaman genetik ditentukan oleh ragam genetik dan standar deviasi ragam genetik $\left(\sigma_{\sigma \mathrm{g}}^{2}\right)$. Keragaman genetik yang luas untuk beberapa karakter pada populasi disebabkan latar belakang genetik populasi yang berbeda (Syukur et al., 2010). Metode seleksi secara efektif dapat digunakan untuk perbaikan karakter dengan nilai KKG tinggi, yaitu nilai yang lebih dari 20\% (Kumar dan Arumugam, 2013b). Dalam penelitian ini, karakter dengan memiliki nilai KKG lebih dari $20 \%$ adalah panjang buah, bobot buah, diameter buah, lebar bekas putik, ukuran calyx, jumlah buah per tanaman dan bobot buah per tanaman (Tabel 1). Hartati et al. (2012) menyatakan bahwa karakter yang memiliki keragaman tinggi berpotensi untuk dimanfaatkan dalam program perbaikan bahan tanaman.

Pendugaan nilai heritabilitas arti luas pada karakter yang diamati berkisar antara 47.34-95.94\%. Elrod dan Stansfield (2002) mengklasifikasikan heritabilitas kedalam tiga kriteria yaitu rendah $\left(\mathrm{h}^{2}{ }_{\mathrm{bs}}<20 \%\right)$, sedang $\left(20 \% \leq \mathrm{h}^{2}{ }_{\mathrm{bs}}\right.$ $<50 \%)$ dan tinggi $\left(\mathrm{h}^{2}{ }_{\text {bs }} \leq 50 \%\right)$. Hanya karakter diameter batang memiliki nilai heritabilitas sedang. Karakter lain yang diamati memiliki nilai heritabilitas tinggi. Nilai heritabilitas yang tinggi menunjukkan bahwa variasi fenotipik antar genotipe lebih banyak dipengaruhi oleh faktor genetik dibandingkan dengan faktor lingkungan (Kumar dan Arumugam, 2013b).

Analisis korelasi dapat mengukur keeratan hubungan antara dua karakter. Tingkat keeratan antar karakter diukur oleh koefisien korelasi. Koefisien korelasi dapat bernilai negataif maupun positif sehingga kisaran nilai berada antara +1 dan -1 . Apabila tidak ada hubungan antar karakter, nilai koefisien korelasi adalah 0 (Acquaah, 2009). Analisis korelasi fenotipik antar karakter disajikan pada Tabel 2. Hasil uji tersebut menunjukkan bahwa karakter komponen hasil seperti panjang buah, bobot buah, diameter buah, dan jumlah buah per tanaman memiliki korelasi positifyang nyata terhadap karakter bobot buah per tanaman. Seleksi serempak terhadap karakter komponen hasil tersebut dapat membawa peningkatan daya hasil karena saling berkorelasi positif. Karakter lain yang memiliki korelasi positif yang nyata terhadap bobot buah per tanaman adalah umur berbunga, umur berbuah, diameter batang, tinggi tanaman dan ukuran calyx. Hasil yang serupa ditemukan pada penelitian Shinde et al. (2012). Hasil korelasi negatif terhadap bobot buah per tanaman terdapat pada karakter lebar bekas putik.

Karakter jumlah buah per tanaman memiliki korelasi yang negatif dengan panjang buah, bobot buah dan diameter buah. Jumlah buah per tanaman yang sedikit akan menyebabkan buah menjadi lebih berat dan besar karena memperoleh hasil fotosintat yang lebih banyak. Hal ini sejalan dengan hasil penelitian yang dilakukan oleh Thangamani dan Jansirani (2012).

Korelasi secara umum menunjukkan keeratan hubungan antara pasangan karakter yang diamati namun

Tabel 1. Rekapitulasi komponen ragam dan heritabilitas 12 karakter tanaman terung

\begin{tabular}{lrrcccc}
\hline \multirow{2}{*}{ Karakter } & \multicolumn{5}{c}{ Komponen ragam dan heritabilitas } \\
\cline { 2 - 7 } & \multicolumn{1}{c}{$\sigma_{\mathrm{g}}^{2}$} & $2 \sigma_{\sigma 2 \mathrm{~g}}$ & $\mathrm{KKG}(\%)$ & Kriteria KKG & $\mathrm{h}_{\left.{ }_{\mathrm{bs}}{ }^{2} \%\right)}$ & ${\text { Kriteria } \mathrm{h}^{2}{ }_{\mathrm{bs}}}$ \\
\hline UBN & 7.009 & 4.569 & 5.35 & Luas & 85.25 & Tinggi \\
UB & 13.596 & 8.919 & 5.00 & Luas & 84.73 & Tinggi \\
PB & 63.722 & 32.707 & 48.01 & Luas & 95.94 & Tinggi \\
BB & $9,716,504$ & $5,371,049$ & 56.81 & Luas & 89.16 & Tinggi \\
DB & 120.107 & 66.544 & 20.60 & Luas & 88.98 & Tinggi \\
DBT & 0.406 & 0.432 & 4.06 & Sempit & 47.34 & Sedang \\
TT & 36.853 & 29.893 & 7.49 & Luas & 61.50 & Tinggi \\
PT & 0.949 & 0.525 & 19.10 & Luas & 89.05 & Tinggi \\
LBP & 0.066 & 0.037 & 51.84 & Luas & 88.06 & Tinggi \\
UC & 1.309 & 0.681 & 26.44 & Luas & 94.69 & Tinggi \\
JBT & 5.44 & 3.413 & 40.49 & Luas & 88.52 & Tinggi \\
BBT & $67,402,677$ & $55,356,123$ & 33.04 & Luas & 68.16 & Tinggi \\
\hline
\end{tabular}

Keterangan: $\sigma_{\mathrm{g}}^{2}=$ ragam genetik, $2 \sigma_{\sigma 2 \mathrm{~g}}=$ standar deviasi ragam genetik, $\mathrm{KKG}=$ koefisien keragaman genetik, $\mathrm{h}_{\mathrm{bs}}^{2}=$ heritabilitas arti luas, $\mathrm{UB} \mathrm{g} N=$ umur berbunga, $\mathrm{UB}=$ umur berbuah, $\mathrm{PB}=$ panjang buah, $\mathrm{BB}=$ bobot buah, $\mathrm{DB}=$ diameter buah, $\mathrm{DBT}=$ diameter batang, $\mathrm{TT}=$ tinggi tanaman, $\mathrm{PT}=$ panjang tangkai, $\mathrm{LBP}=$ lebar bekas putik, $\mathrm{UC}=$ ukuran calyx, $\mathrm{JBT}=$ jumlah buah per tanaman, $\mathrm{BBT}=$ bobot buah per tanaman 
Tabel 2. Koefisien korelasi antar karakter pada terung

\begin{tabular}{|c|c|c|c|c|c|c|c|c|c|c|c|c|}
\hline & UBN & UB & PB & $\mathrm{BB}$ & DB & DBT & $\mathrm{TT}$ & PT & BP & $\mathrm{UC}$ & JBT & BBT \\
\hline UBN & - & $0.821 * *$ & 0.109 & $0.398 * *$ & $0.449 * *$ & $0.689 * *$ & $0.535^{* *}$ & $-0.251 *$ & 0.175 & $0.229^{*}$ & $0.448 * *$ & $0.544 * *$ \\
\hline UB & & - & 0.098 & $0.279 *$ & $0.382 * *$ & $0.906^{* *}$ & $0.789 * *$ & -0.1 & 0.153 & 0.144 & $0.449 * *$ & $0.520 * *$ \\
\hline PB & & & - & $0.771 * *$ & $0.243^{*}$ & 0.114 & -0.077 & $0.444 * *$ & $-0.348 * *$ & $0.838 * *$ & -0.224 & $0.701 * *$ \\
\hline $\mathrm{BB}$ & & & & - & $0.725 * *$ & $0.279 *$ & 0.072 & $0.283^{*}$ & 0.102 & $0.821 * *$ & $-0.287^{*}$ & $0.752 * *$ \\
\hline DB & & & & & - & $0.408 * *$ & $0.292 *$ & 0.023 & $0.462 * *$ & $0.469 * *$ & -0.217 & $0.514 * *$ \\
\hline DBT & & & & & & - & $0.887 * *$ & -0.117 & 0.147 & 0.108 & $0.459 * *$ & $0.570 * *$ \\
\hline TT & & & & & & & - & -0.142 & 0.088 & -0.098 & $0.541 * *$ & $0.421 * *$ \\
\hline PT & & & & & & & & - & -0.174 & $0.485 * *$ & $-0.499 * *$ & 0.052 \\
\hline LBP & & & & & & & & & - & -0.139 & $-0.279^{*}$ & -0.209 \\
\hline $\mathrm{UC}$ & & & & & & & & & & - & $-0.365 * *$ & $0.631 * *$ \\
\hline JBT & & & & & & & & & & & - & $0.312 * *$ \\
\hline BBT & & & & & & & & & & & & - \\
\hline
\end{tabular}

Keterangan: * = berpengaruh nyata pada $\alpha=5 \%, * *=$ berpengaruh nyata pada $\alpha=1 \%$, UBN $=$ umur berbunga, UB $=$ umur berbuah, $\mathrm{PB}=$ panjang buah, $\mathrm{BB}=$ bobot buah, $\mathrm{DB}=$ diameter buah, $\mathrm{DBT}=$ diameter batang, $\mathrm{TT}=$ tinggi tanaman, $\mathrm{PT}=$ panjang tangkai, $\mathrm{LBP}=$ lebar bekas putik, $\mathrm{UC}=$ ukuran calyx, $\mathrm{JBT}=$ jumlah buah per tanaman, $\mathrm{BBT}=$ bobot buah per tanaman

tidak dapat memprediksi kriteria seleksi yang efektif dengan tepat. Analisis lintas dapat mengidentifikasi hubungan sebab-akibat yang disebabkan suatu karakter ke karakter yang lain. Analisis ini dapat menyajikan pengaruh langsung, pengaruh tidak langsung maupun pengaruh total (Hefny, 2011). Pengaruh langsung merupakan pengaruh suatu karakter terhadap daya hasil tanpa melalui karakter lain. Pengaruh tidak langsung merupakan pengaruh suatu karakter terhadap daya hasil melalui karakter lain. Pengaruh total adalah jumlah gabungan nilai pengaruh langsung maupun tidak langsung suatu karakter.

Bobot buah per tanaman merupakan hasil dari interaksi komponen hasil. Analisis lintas dapat menyajikan informasi penting mengenai bagaimana berbagai macam karakter komponen hasil maupun karakter agronomis dapat mempengaruhi hasil bobot buah per tanaman. Pengaruh langsung dari karakter yang diamati terhadap daya hasil dapat memberikan gambaran tentang efektivitas seleksi terhadap karakter tersebut untuk memperbaiki daya hasil. Apabila nilai korelasi dan pengaruh langsung suatu karakter dengan daya hasil kurang lebih sama besarnya, maka seleksi langsung terhadap karakter tersebut akan efektif untuk meningkatkan daya hasil (Shinde et al., 2012).

Hasil analisis lintas disajikan di Tabel 3. Karakter yang mempunyai pengaruh langsung positif terhadap bobot buah per tanaman adalah panjang buah, bobot buah, diameter

Tabel 3. Nilai pengaruh langsung dan tidak langsung 11 karakter terhadap bobot buah per tanaman terung

\begin{tabular}{|c|c|c|c|c|c|c|c|c|c|c|c|c|c|}
\hline \multirow{2}{*}{ Karakter } & \multirow{2}{*}{$\begin{array}{l}\text { Pengaruh } \\
\text { langsung }\end{array}$} & \multicolumn{11}{|c|}{ Pengaruh tidak langsung } & \multirow{2}{*}{ Total } \\
\hline & & UBN & UB & PB & $\mathrm{BB}$ & DB & DBT & TT & PT & $\mathrm{BP}$ & $\mathrm{UC}$ & JBT & \\
\hline UBN & -0.142 & - & -0.116 & -0.015 & -0.056 & -0.064 & -0.098 & -0.076 & 0.036 & -0.025 & -0.033 & -0.064 & -0.653 \\
\hline UB & -0.029 & -0.024 & - & -0.003 & -0.008 & -0.011 & -0.026 & -0.023 & 0.003 & -0.004 & -0.004 & -0.013 & -0.141 \\
\hline PB & 0.294 & 0.032 & 0.029 & - & 0.226 & 0.071 & 0.033 & -0.023 & 0.130 & -0.102 & 0.246 & -0.066 & 0.871 \\
\hline $\mathrm{BB}$ & 0.437 & 0.174 & 0.122 & 0.337 & - & 0.317 & 0.122 & 0.031 & 0.124 & 0.045 & 0.358 & -0.125 & 1.940 \\
\hline DB & 0.209 & 0.094 & 0.08 & 0.051 & 0.152 & - & 0.085 & 0.061 & 0.005 & 0.097 & 0.098 & -0.045 & 0.887 \\
\hline DBT & 0.197 & 0.136 & 0.179 & 0.022 & 0.055 & 0.080 & - & 0.175 & -0.023 & 0.029 & 0.021 & 0.091 & 0.962 \\
\hline $\mathrm{TT}$ & -0.012 & -0.007 & -0.010 & 0.001 & -0.001 & -0.004 & -0.011 & - & 0.002 & -0.001 & 0.001 & -0.007 & -0.048 \\
\hline PT & -0.030 & 0.007 & 0.003 & -0.013 & -0.008 & -0.001 & 0.003 & 0.004 & - & 0.005 & -0.014 & 0.015 & -0.028 \\
\hline BP & -0.074 & -0.013 & -0.011 & 0.026 & -0.008 & -0.034 & -0.011 & -0.007 & 0.013 & - & 0.010 & 0.021 & -0.088 \\
\hline UC & 0.152 & 0.035 & 0.022 & 0.127 & 0.125 & 0.071 & 0.016 & -0.015 & 0.074 & -0.021 & - & -0.055 & 0.530 \\
\hline JBT & 0.561 & 0.251 & 0.252 & -0.125 & -0.161 & -0.122 & 0.258 & 0.304 & -0.280 & -0.157 & -0.205 & - & 0.576 \\
\hline Sisa & 0.242 & & & & & & & & & & & & \\
\hline
\end{tabular}

Keterangan: $\mathrm{UBN}=$ umur berbunga, $\mathrm{UB}=$ umur berbuah, $\mathrm{PB}=$ panjang buah, $\mathrm{BB}=$ bobot buah, $\mathrm{DB}=$ diameter buah, $\mathrm{DBT}=$ diameter batang, $\mathrm{TT}=$ tinggi tanaman, $\mathrm{PT}=$ panjang tangkai, $\mathrm{LBP}=$ lebar bekas putik, $\mathrm{UC}=$ ukuran calyx, $\mathrm{JBT}=$ jumlah buah per tanaman, BBT = bobot buah per tanaman 
buah, diameter batang, ukuran calyx dan jumlah buah per tanaman. Karakter yang memiliki pengaruh langsung terbesar terhadap bobot buah per tanaman adalah karakter jumlah buah per tanaman dan karakter bobot buah. Karakter bobot buah juga memiliki nilai pengaruh total terbesar di antara karakter lainnya. Nilai pengaruh total bobot buah bisa melebih angka 1 . Hal tersebut dapat diakibatkan oleh adanya multikoliniearitas atau adanya dua atau lebih variabel bebas yang mempunyai tingkat korelasi tinggi. Jika hal ini terjadi, maka kita akan mendapatkan standard error yang besar dari koefisien beta (Sarwono, 2011).

Lenka dan Mishra (1973) mengkategorikan nilai pengaruh analisis lintas menjadi lima kategori, yaitu nilai 0.00 hingga 0.09 tergolong dapat diabaikan, nilai 0.10 hingga 0.19 tergolong rendah, nilai 0.20 hingga 0.29 tergolong sedang, nilai 0.30 hingga 0.99 tergolong tinggi dan nilai lebih dari 1.00 tergolong sangat tinggi. Pada penelitian ini, karakter jumlah buah per tanaman dan bobot buah memiliki nilai pengaruh langsung yang tinggi terhadap karakter produksi bobot buah per tanaman. Karakter panjang buah dan diameter buah memiliki nilai pengaruh langsung sedang sementara nilai pengaruh langsung diameter batang dan panjang calyx tergolong rendah.

Karakter tinggi tanaman, umur berbunga dan umur berbuah memiliki pengaruh tidak langsung terhadap bobot buah per tanaman melalui karakter jumlah buah per tanaman. Karakter panjang buah, diameter buah dan ukuran calyx juga memiliki pengaruh tidak langsung melalui karakter bobot buah. Enam karakter tersebut dapat digunakan sebagai karakter seleksi tidak langsung terhadap karakter bobot buah per tanaman. Model analisis sidik lintas ini dapat menjelaskan hubungan komponen yang mempengaruhi bobot buah per tanaman sebesar 0.76 . Nilai sisa dari hasil analisis lintas sebesar 0.24. Nilai sisa adalah pengaruh karakter-karakter lain yang tidak dapat dijelaskan oleh model atau tidak dimasukkan ke dalam analisis lintas (Nasution, 2010).

Analisis sidik lintas, bersama dengan uji korelasi dan pedugaan nilai heritabilitas dapat digunakan untuk mencari karakter yang dapat digunakan sebagai kriteria seleksi yang efektif. Yunianti et al. (2010) menyatakan bahwa penentuan karakter-karakter yang dapat dijadikan kriteria seleksi efektif dapat dilihat dari (1) besarnya nilai pengaruh langsung, (2) hasil korelasi antar karakter yang bertanda sama dengan hasil analisis lintas dan (3) selisih yang kecil $(<0.05)$ antara nilai korelasi dengan nilai pengaruh lansung.

Kumar dan Arumugam (2013a) menambahkan bahwa karakter seleksi yang efektif memiliki nilai pengaruh langsung yang tinggi, korelasi yang nyata dan nilai heritabilitas yang tinggi. Apabila melihat kriteria tersebut, maka karakter bobot buah, diameter buah dan jumlah buah per tanaman dapat dijadikan karakter untuk menentukan kriteria seleksi yang efektif dalam usaha merakit terung berproduksi tinggi. Ketiga karakter tersebut memiliki hasil korelasi dan analisis lintas yang positif dan searah dengan karakter bobot buah per tanaman. Karakter bobot buah memiliki nilai pengaruh langsung sebesar 0.437 dan korelasi yang nyata sebesar 0.752 terhadap bobot buah per tanaman. Sementara karakter diameter buah memiliki nilai pengaruh langsung sebesar 0.209 dan korelasi yang nyata sebesar 0.514. Jumlah buah per tanaman memiliki nilai pengaruh langsung sebesar 0.561 dan nilai korelasi yang nyata sebesar 0.312. Meskipun selisih nilai korelasi dan nilai pengaruh langsung tidak lebih kecil dari 0.05 , namun selisih kedua nilai dari ketiga karakter tersebut lebih kecil dibandingkan dengan karakter lainnya yang diamati.

\section{KESIMPULAN}

Sebelas karakter memiliki heritabilitas tinggi dan koefisien keragaman genetik tinggi, yaitu umur berbunga, umur berbuah, panjang buah, bobot buah, diameter buah, tinggi tanaman, panjang tangkai, lebar bekas putik, ukuran calyx, jumlah buah per tanaman dan bobot buah per tanaman. Hasil analisis korelasi dan analisis lintas menunjukkan bahwa panjang buah, bobot buah, diameter buah, diameter batang, ukuran calyx dan jumlah buah per tanaman memiliki pengaruh langsung positif terhadap karakter bobot buah per tanaman. Bobot buah, diameter buah dan jumlah buah per tanaman merupakan karakter yang tepat dalam penentuan kriteria seleksi untuk merakit terung berproduksi tinggi.

\section{UCAPAN TERIMA KASIH}

Terima kasih kepada PUSNAS dan Pusat Studi Hortikultura Tropis (PKHT), Institut Pertanian Bogor atas pembiayaan penelitian dan ketersediaan bahan genetik.

\section{DAFTAR PUSTAKA}

Acquaah, G. 2009. Principles of Plant Genetics and Breeding. John Wiley \& Sons, Hoboken, New Jersey, USA.

Akanitapichat, P., K. Phraibung, K. Nuchklang, S. Prompitakkul. 2010. Antioxidant and hepatoprotective activities of five eggplant varieties. Food and Chemical Toxicology 48:3017-3021.

Begum, F., A.K.M.A. Islam, M.G. Rasul, M.A.K. Mian, M.M. Hossain. 2013. Morphological diversity of eggplant (Solanum melongena) in Bangladesh. Emir. J. Food Agric. 25:45-51.

Bansal, S., A.K. Mehta. 2008. Genotypic correlation and path analysis in brinjal (Solanum melongena L.). Nat. J. Plant Improvement. 10:34-36.

Elrod, S.L., W.D. Stansfield. 2002. Schaum's Outline of Theory and Problems of Genetics. McGraw-Hill, New York City, New York, USA.

Hartati, R.S., A. Setiawan, B. Heliyanto, Sudarsono. 2012. Keragaman genetik, heritabilitas, dan korelasi antar karakter 10 genotipe terpilih jarak pagar (Jatropha curcas L.). Jurnal Littri. 18:74-80. 
Hefny, M. 2011. Genetic parameters and path analysis of yield and its components in corn inbred lines (Zea mays L.) at different sowing dates. Asian J. Crop Sci. 3:106-117.

Hidayatullah, S.A. Jatoi, A. Ghafoor, T. Mahmood. 2008. Path coefficient analysis of yield component in tomato (Lycopersicon esculentum). Pak. J. Bot. 40:627-635.

Khayatnezhad, M., R. Shahriari, R. Gholamin, S. Jamaatie-Somarin, R. Zabihi-e-Mahmoodabad. 2011. Correlation and path analysis between yield and yield components in potato (Solanum tuberosum L.). Middle-East J. Sci. Res. 7:17-21.

Kumar, S.R., T. Arumugam. 2013a. Correlation and path coefficient analysis for some yield-related traits in F2 segregating population of eggplant. Internat. J. Veg. Sci. 19:334-341.

Kumar, S.R., T. Arumugam. 2013b. Variability, heritability and genetic advance for fruit yield, quality and pest and disease incidence in eggplant. Veg. Sci. 40:111113.

Kumar, S.R., T. Arumugam, S. Balakrishnan, C.R. Anandakumar. 2013. Variability in the segregating generation of eggplant for earliness and yield. Pakistan J. Biol. Sci. 16:1122-1129.

Lenka, D., B. Mishra. 1973. Path coefficient analysis of yield in rice varieties. Indian J. Agric. Sci. 43:376379.

Luby, J.J., D.V. Shaw. 2009. Plant breeders' perspectives on improving yield and quality traits in horticultural food crops. Hort Sci. 44:20-22.
Nasution, M.A. 2010. Analisis korelasi dan sidik lintas antara karakter morfologi dan komponen buah tanaman nenas (Ananas comosus L. Merr.). Crop Agro. 3:1-9.

Pinaria, A., A. Baihaki, R. Setiamihardja, A.A. Daradjat. 1995. Variabilitas genetik dan heritabilitas karakterkarakter biomassa 53 genotipe kedelai. Zuriat 6:8892.

Sarwono, J. 2011. Mengenal path analysis: sejarah, pengertian dan aplikasi. Jurnal Ilmiah Manajemen Bisnis 11:285-296.

Shinde, K.G., U.M. Birajdar, M.N. Bhalekar, B.T. Patil. 2012. Correlation and path analysis in eggplant (Solanum melongena L.). Veg. Sci. 39:108-110.

Singh, R.K., B.D. Chaudhary. 1979. Biometrical Methods in Quantitative Genetic Analysis. Kalyani Publishers, Ludhiana. New Delhi.

Syukur, M., S. Sujiprihati, R. Yunianti, K. Nida. 2010. Pendugaan komponen ragam, heritabilitas dan korelasi untuk menentukan kriteria seleksi cabai (Capsicum annuum 1.) populasi F5. J. Hort. Indonesia $1: 74-80$.

Thangamani, C., P. Jansirani. 2012. Correlation and path coefficient analysis studies on yield and attributing characters in brinjal (Solanum melongena L.). Electron. J. Plant Breed. 3:939-944.

Yunianti, R., S. Sastrosumarjo, S. Sujiprihati, M. Surahman, S.H. Hidayat. 2010. Kriteria seleksi untuk perakitan varietas cabai tahan Phytophthora capsici Leonian. J. Agron. Indonesia 38:122-129. 